\title{
Physical and oxidative stability of high fat fish oil-in-water emulsions stabilized with sodium caseinate and phosphatidylcholine as emulsifiers
}

Yesiltas, Betül; García Moreno, Pedro Jesús; Sørensen, Ann-Dorit M.; Akoh, Casimir C.; Jacobsen, Charlotte

Published in:

Food Chemistry

Link to article, DOI:

10.1016/j.foodchem.2018.09.172

Publication date:

2019

Document Version

Peer reviewed version

Link back to DTU Orbit

Citation (APA):

Yesiltas, B., García Moreno, P. J., Sørensen, A-D. M., Akoh, C. C., \& Jacobsen, C. (2019). Physical and oxidative stability of high fat fish oil-in-water emulsions stabilized with sodium caseinate and phosphatidylcholine as emulsifiers. Food Chemistry, 276, 110-118. https://doi.org/10.1016/j.foodchem.2018.09.172

\section{General rights}

Copyright and moral rights for the publications made accessible in the public portal are retained by the authors and/or other copyright owners and it is a condition of accessing publications that users recognise and abide by the legal requirements associated with these rights.

- Users may download and print one copy of any publication from the public portal for the purpose of private study or research.

- You may not further distribute the material or use it for any profit-making activity or commercial gain

- You may freely distribute the URL identifying the publication in the public portal 


\section{Accepted Manuscript}

Physical and oxidative stability of high fat fish oil-in-water emulsions stabilized with sodium caseinate and phosphatidylcholine as emulsifiers

Betül Yesiltas, Pedro J. García-Moreno, Ann-Dorit M. Sørensen, Casimir C. Akoh, Charlotte Jacobsen

PII: S0308-8146(18)31757-6

DOI: https://doi.org/10.1016/j.foodchem.2018.09.172

Reference: FOCH 23659

To appear in:

Food Chemistry

Received Date:

26 April 2018

Revised Date: 5 September 2018

Accepted Date: 29 September 2018

Please cite this article as: Yesiltas, B., García-Moreno, P.J., Sørensen, A.M., Akoh, C.C., Jacobsen, C., Physical and oxidative stability of high fat fish oil-in-water emulsions stabilized with sodium caseinate and phosphatidylcholine as emulsifiers, Food Chemistry (2018), doi: https://doi.org/10.1016/j.foodchem.2018.09.172

This is a PDF file of an unedited manuscript that has been accepted for publication. As a service to our customers we are providing this early version of the manuscript. The manuscript will undergo copyediting, typesetting, and review of the resulting proof before it is published in its final form. Please note that during the production process errors may be discovered which could affect the content, and all legal disclaimers that apply to the journal pertain. 


\section{Physical and oxidative stability of high fat fish oil-in-water emulsions stabilized with sodium caseinate and phosphatidylcholine as emulsifiers}

Betül Yesiltasa , Pedro J. García-Moreno ${ }^{a}$, Ann-Dorit M. Sørensena, Casimir C. Akoh ${ }^{b}$, Charlotte Jacobsen ${ }^{\text {* }}$

betye@food.dtu.dk, pejeg@food.dtu.dk,adms@food.dtu.dk, cakoh@uga.edu, chja@food.dtu.dk

aDivision of Food Technology, National Food Institute, Technical University of Denmark, Denmark

bDepartment of Food Science and Technology, University of Georgia, Athens, GA, USA ${ }^{*}$ Correspondence: Charlotte Jacobsen, National Food Institute, Technical University of Denmark, Kemitorvet, Building 204, 2800 Kgs. Lyngby, Tel: +45 232790 75; e-mail: chja@food.dtu.dk

\section{Abstract}

The physical and oxidative stability of high-fat omega-3 delivery systems such as fish oil-inwater emulsions stabilized with combinations of sodium caseinate (CAS) and phosphatidylcholine (PC) was optimized. The influence of fish oil content $(50,60$ and $70 \%$, $\mathrm{w} / \mathrm{w})$, amount of total emulsifier CAS+PC $(1.4,2.1$ and $2.8 \%, \mathrm{w} / \mathrm{w})$ and ratio between CAS and PC $(0.4,1.2$ and 2$)$ on physical and oxidative parameters was investigated. Creaming and droplet size significantly decreased when the amount of fish oil, total emulsifier and ratio of CAS to PC were increased. Viscosity decreased significantly with decreasing fish oil content, whereas the ratio of CAS to PC did not have a significant influence. Decreasing the ratio of CAS to PC led to emulsions with a significantly lower concentration of 1-penten-3-ol, 
while no significant effect was found for other volatiles such as (E)-2-pentenal, (E)-2-hexenal and $(E, E)-2,4$-heptadienal.

Keywords: omega-3, o/w emulsions, lipid oxidation, milk protein, phospholipids, optimization

\section{Introduction}

Marine long chain (LC) omega-3 polyunsaturated fatty acids (PUFAs) have been reported to have numerous beneficial effects on health such as decreasing cardiovascular diseases, improving immune system and mental health (Song, Shieh, Wu, Kalueff, Gaikwad \& Su, 2016; Wysoczanski, Sokoła-Wysoczanska, Pekala, Lochynski, Czyz, Bodkowski et al., 2016; Nichols, McManus, Krail, Sinclair \& Miller, 2014). LC omega-3 PUFAs are mainly found in fish and fish products. However, the average daily intake of fish products in Western societies does not reach the required levels to obtain positive impacts on health (Papanikolaou, Brooks, Reider \& Fulgoni III, 2014). Therefore, omega-3 enriched foods have gained increasing attention from consumers who want to maintain a balanced diet. Accordingly, the food industry has looked for new product opportunities and technologies for producing omega-3 enriched foods. Nevertheless, omega-3 PUFAs are highly prone to oxidation, which negatively affects taste, smell and texture of omega- 3 enriched food products and decreases consumers' acceptance (Kolanowski, Jaworska \& Weißbrodt, 2007; Bermudez-Aguirre \& Barbosa-Canovas, 2011).

Fish oil-in-water emulsions are one of the delivery systems that have been used for delivering LC omega-3 PUFAs, while providing protection against oxidation if the emulsion recipe is optimal. Many studies have been performed on physical and oxidative stability of low fat (530\%) emulsions (McClements, Decker \& Weiss, 2007; Waraho, McClements \& Decker, 2011). Nevertheless, only a few studies have been reported on high fat $(50-70 \%)$ emulsions 
(Horn, Nielsen, Andersen, Søgaard, Horsewell \& Jacobsen, 2011; Horn, Nielsen \& Jacobsen, 2012; Yesiltas, García-Moreno, Sørensen \& Jacobsen, 2017). High fat delivery emulsions with high viscosity are preferred for enrichment of food systems with high oil content (e.g., mayonnaise, dressings and cream cheese), since their incorporation will have a reduced impact on the texture of the product. Moreover, a lower amount of high fat emulsions would be required for a certain level of food enrichment compared to low fat emulsions. If viscosity of high fat emulsions can be decreased they may also be applicable to low-viscous products (e.g. milk, soft-drinks, and juices), while reducing possible negative effects on the texture and rheology of the final product.

Emulsifiers, amongst others, are used for decreasing the interfacial energy between oil and water molecules by being adsorbed at the interface, which makes emulsion energetically less unfavorable (McClements, 1999). Understanding the structure, composition and mechanical properties of the interface seems essential for controlling the physico-chemical stability properties of food emulsions. There have been many studies, which reported that combined use of emulsifiers provided advantages in terms of improving physical and oxidative stability of emulsions compared to single use of an emulsifier (Fang \& Dalgleish, 1996; Sünder, Scherze \& Muschiolik, 2001; Gao, Huang, Zhao, Yao, Zhang, Fang, Nishinari, Philips \& Yang, 2017).

Sodium caseinate (CAS) is a protein product, which is commonly used as an emulsifier in food products. Horn et al. (2012) reported that CAS provides a good physical barrier at the oilwater interface, which prevents prooxidant (e.g. metal ions) permeation from water phase to oil phase. Additionally, CAS showed metal chelating activity both at the oil-water interface and in the water phase (Diaz, Dunn, McClements \& Decker, 2003; Horn, Barouh, Nielsen, Baron 
\& Jacobsen, 2013). However, high fat emulsions produced with protein-based emulsifiers have high viscosity, which might hamper the usage of emulsions in food enriched applications (Horn et al., 2011). Thus, combined usage of proteins and phospholipids was applied as a strategy for reducing the viscosity of the emulsions (García-Moreno, Horn \& Jacobsen, 2014). Phosphatidylcholine (PC) is a zwitterionic phospholipid extracted from egg or soybean, which is widely used as an emulsifier in oil-in-water emulsions (García-Moreno et al., 2014; Scuriatti, Tomás \& Wagner, 2003; Sui, Li, Wang, Qi, Zou, Li \& Jiang, 2016; Magnusson, Nilsson \& Bergenståhl, 2016). Furthermore, findings of previous researchers indicated that PC showed antioxidant activity by donating protons to stabilize radicals, stabilizing peroxyl radicals to yield stable compounds (e.g. trimethylammonium oxide) and chelating metals due to the amino group (García-Moreno et al., 2014; Berton-Carabin, Ropers \& Genot, 2014; Bandarra, Campos, Batista, Nunes \& Empis, 1999). Nevertheless, phospholipids as a sole emulsifier have been reported to cause an insufficient physical stability and result in phase separation (Sznitowka, Janicki, Dabrowska \& Zurowska-Pryczkowska, 2001). Therefore, some studies have suggested the use of $P C$ or lecithin (mainly containing PC) together with other emulsifiers such as sodium caseinate or whey protein in order to increase emulsion stability by the formation of a complex interfacial film, which potentially helps to improve the physical and oxidative stability of emulsions (Fang et al., 1996; Sünder et al., 2001; García-Moreno et al., 2014; Xue \& Zhong, 2014). However, there are no studies that used a systematic approach with a statistical experimental design such as Box Behnken to study the combined effects of PC and CAS in high fat oil-in-water emulsions.

In this study, we hypothesize that using optimum combinations of CAS and PC as emulsifiers will allow the obtainment of physically and oxidatively stable high-fat omega-3 delivery 
emulsions. This is due to the antioxidant capacity that both emulsifiers can exhibit at the interface and in the aqueous phase as well as on the potential formation of an interface with enhanced structural properties. Moreover, the use of CAS and PC combinations, which implies a reduction in the amount of CAS used, may lead to high fat fish oil-in-water emulsions with a reduced viscosity, which is desired for an easy application in a wide range of products. Box-Behnken`s experimental design and response surface methodology (RSM) were used to investigate the effects of fish oil content, total CAS and PC content, and the ratio of CAS to PC on the physical and oxidative stability of the high-fat emulsions.

\section{Materials and methods}

\subsection{Materials}

Cod liver oil was provided by Maritex A/S, a subsidiary of TINE, BA (Sortland, Norway), and stored at $-40^{\circ} \mathrm{C}$ until use. The fatty acid (\% of total fatty acids) content of the fish oil as determined and supplied by the manufacturer was as follows: C14:0 (3.02), C16:0 (8.91), C16:1 n-7 (8.20), C18:0 (1.88), C18:1 n-9 (16.00), C18:1 n-7 (5.16), C18:2 n-6 (1.79), C18:3 n-3 (0.84), C20:1 n-9 (11.59), C20:5n-3 (9.27), C22:1 n-11 (6.06), C22:6 n-3 (11.64) and other fatty acids (15.64). Phosphatidylcholine (PC) extracted from soybean (LIPOID S100) was kindly provided by Lipoid GmbH, Germany. Analysis of certificate of the Lipoid S100 reported that $97.1 \%$ of the product is phosphatidylcholine (based on dry weight). There is $0.20 \%$ DL-a-Tocopherol, which is an antioxidant. Other lipid molecules were also reported as follows: $1.2 \%$ lysophosphatidylcholine, $0.5 \% \mathrm{~N}$-acyl-phosphatidylethanolamine, lower than $0.1 \%$ phosphatidylethanolamine, lower than $0.1 \%$ phosphatidylinositol, $0.8 \%$ non-polar lipids, and $0.3 \%$ triglycerides. PC had initial peroxide value (PV) of $1.58 \mathrm{meq} / \mathrm{kg}$ oil and its fatty acid (in \% of total fatty acids) composition was as follows: $16: 0$ (13.42), 18:1 n-9 (10.97), 18:2 n-6 
(62.61), 18:3 n-6 (6.96), and others (5.51). Initial PV of the fish oil was 0.12 meq peroxide/kg oil. Sodium caseinate (Miprodan 30) was provided by Arla Foods Ingredients amba (Viby J, Denmark). Protein content of sodium caseinate was reported as $92 \%(\mathrm{~N} \times 6.38)$.

\subsection{Emulsion preparation and sampling}

Different amounts of CAS and PC (see Table 1) were dissolved/dispersed in distilled water and stirred overnight at $500 \mathrm{rpm}$ at $4^{\circ} \mathrm{C}$. The $\mathrm{pH}$ of the aqueous phases was adjusted to 7.0 using $2 \mathrm{M} \mathrm{HCl}$ or $2 \mathrm{M} \mathrm{NaOH}$. Emulsions $(500 \mathrm{~g}$ ) were produced using a Stephan Universal mixer (Stephan, UMC5, Hameln, Germany) which was equipped with an emulsification blade as described by Horn et al (2011). Fish oil concentration at three different levels (50, 60 and $70 \%, w / w$ of total emulsion), total emulsifier content (CAS+PC) at three different levels (1.4,

2.1 and $2.8 \%, \mathrm{w} / \mathrm{w}$ of total emulsion) and ratio of CAS to PC at three different levels $(0.4,1.2$ and 2.0, w/w) were the three factors studied. A Box-Behnken`s experimental design was carried out with fifteen emulsions in total, including 3 replicates of the central point (see Table 1). $\mathrm{Fe}^{2+}\left(0.03 \% \mathrm{FeSO}_{4} \cdot 7 \mathrm{H}_{2} \mathrm{O}\right.$ dissolved in water, corresponding to approx. $100 \mu \mathrm{M}$ in the final emulsion) and $0.05 \%$ sodium azide were added into the emulsions in order to accelerate oxidation and prevent microbial growth, respectively, right after the emulsions were produced. For the storage, each emulsion was divided into portions of $85 \mathrm{~g}$ and placed in $100 \mathrm{~mL}$ blue cap bottles. There was one bottle for each sampling day. Emulsions were stored for 12 days at room temperature in darkness and sampling was performed on days $0,2,5,8$ and 12 . Peroxide value and tocopherols were analyzed at all sampling points. All samples for analysis of oxidation parameters were taken from blue capped bottles and put in brown colored bottles 
where they were stored at $-40 \mathrm{C}$ until analysis. Emulsions were stirred with a spoon before sampling.

\subsection{Characterization of emulsions}

\subsubsection{Droplet size}

Particle size of the emulsions was measured on days 1 and 12 by laser diffraction (Mastersizer 2000, Malvern Instruments Ltd., Worcestershire, UK). The method used was described by Let, Jacobsen \& Meyer (2007) and Horn et al. (2011). Samples were collected directly from the bottles where the emulsions were stored. There were separate bottles for each sampling day. Right before sampling, emulsion was mixed with a spoon and samples were collected. Volume weighted mean diameter of the samples were calculated according to the equation 2:

$D[4,3]=\Sigma n_{i} d_{i}^{4} / \sum n_{i} d_{i}^{3}($ Equation 2)

Measurements were carried out in duplicates.

\subsubsection{Apparent viscosity}

Apparent viscosity was measured on days 1 and 12 using a stress-controlled rheometer (Stresstech, Reologica Instruments AB, Lund, Sweden). CC25 standard bob cup system was used and samples were placed in a vessel which was set at $25^{\circ} \mathrm{C}$. Shear stress range was set from 0.0125 to $50 \mathrm{~Pa}$ for each measurement. Apparent viscosity results were obtained at a shear rate of $20 \mathrm{~s}^{-1}$ and expressed in $\mathrm{mPa} \cdot \mathrm{s}$. Measurements were carried out in duplicates.

\subsubsection{Creaming index}

Creaming index $(\mathrm{Cl})$ was followed on days $1,5,8,12$ in the $100 \mathrm{~mL}$ blue cap bottles. $\mathrm{Cl}$ was calculated using equation 1 :

$\mathrm{Cl}(\%)=(\mathrm{b} / \mathrm{a}) \times 100($ Equation 1$)$ 
where (a) is the height of total emulsion and (b) is the height of water phase separated at the bottom of the bottle. $\mathrm{Cl}$ was calculated as in percentage for each emulsion sample for each sampling point without replicates.

\subsection{Lipid oxidation in emulsions}

\subsubsection{Primary oxidation products - peroxide value (PV)}

Primary oxidation products were determined by preparing a lipid extract which was previously described by Bligh and Dyer (1959). Five grams of emulsion and a reduced amount of solvent (60 $\mathrm{mL}$ of methanol and chloroform, 1:1; v/v) were used for each extraction. PV was subsequently performed on the lipid extracts according to IDF standard method by colorimetric determination of iron thiocyanate on a spectrophotometer (Shimadzu, UV mini 1240, Kyoto, Japan) at $500 \mathrm{~nm}$ (Shantha \& Decker, 1994). All measurements were carried out in duplicates.

\subsubsection{Tocopherol content - High Pressure Liquid Chromatography (HPLC)}

Tocopherol contents of emulsions were prepared using lipid extracts (see section 2.4.1), which were further evaporated and re-dissolved in heptane and then analyzed by HPLC (Agilent 1100 Series, Waldbronn, Germany; Column: Waters Spherisorb $3 \mu \mathrm{m}$ Silica; $4.6 \mathrm{x}$ $150 \mathrm{~mm}, \mathrm{MA}$, USA). Analysis was carried out according to the official AOCS method (1998) in duplicates.

\subsubsection{Secondary volatile oxidation products - dynamic headspace (DHS) GC-MS}

Secondary volatile oxidation products were evaluated on days 0 and 12 according to the method described by Jacobsen, Meyer \& Adler-Nissen (1999). Emulsion sample (4 g) was mixed with $2 \mathrm{~mL}$ antifoam and $10 \mathrm{~mL}$ distilled water in a $100 \mathrm{~mL}$ purge bottle which was heated in a water bath at $60^{\circ} \mathrm{C}$ while purging with nitrogen (flow $150 \mathrm{~mL} / \mathrm{min}, 30 \mathrm{~min}$ ). Volatile 
compounds present in the emulsion samples were trapped on Tenax GR tubes and separated in a gas chromatograph (Agilent Technologies, 6890N Network GC System, DE, USA) on a $30 \mathrm{~m}$ DB 1701 fused silica capillary column (0.25 mm i.d., $1 \mu \mathrm{m}$ film thickness, Agilent Technologies, J\&W GC Columns, CA, USA). The oven program had an initial temperature of $45^{\circ} \mathrm{C}$ for $5 \mathrm{~min}$, increasing at $1.5^{\circ} \mathrm{C} / \mathrm{min}$ until $55^{\circ} \mathrm{C}$, then at $2.5^{\circ} \mathrm{C} / \mathrm{min}$ until $90^{\circ} \mathrm{C}$, and at $12^{\circ} \mathrm{C} / \mathrm{min}$ until $220^{\circ} \mathrm{C}$, where the temperature was held for $4 \mathrm{~min}$. Mass spectrometry (Agilent 5973 Network Mass Selective Detector, Agilent Technologies, electron ionization mode, 70 $\mathrm{eV}$; mass to charge ratio scan between 30 and 250) was used for the analysis of each individual volatile compound and identified by MS-library searches (Wiley $138 \mathrm{~K}$, John Wiley and Sons, Hewlett-Packard). Quantification was performed using calibration curves which were prepared by injecting external standards (2-ethyl-furan, 1-penten-3-one, 1-penten-3-ol, (E)-2-pentenal, hexanal, (E)-2-hexenal, (Z)-4-heptenal, 2-pentyl-furan, (E)-2-heptenal, benzaldehyde, (E,E)-2,4-heptadienal, nonanal and (E,Z)-2,6-nonadienal) directly on the Tenax GR tubes. Measurements were made in triplicate on each sample. Results were expressed in $\mathrm{ng} / \mathrm{g}$ emulsion.

\subsection{Box-Behnken's experimental design, RSM and statistical analysis}

A 3-factor Box-Behnken design is a RSM design, which includes sets of runs in which pair of factors is varied between their low (-1) and high (+1) levels, while the other experimental factor is held at the medium (0) level. Three center-points $(0,0,0)$ are added to the design in order to check the differences between replicates. In this study, 3 different factors (fish oil content, total content of CAS + PC and the ratio between CAS and PC) were included at 3 different levels, as shown in Table 1. 
Statgraphics XVII (Statpoint Technologies, Inc., Virginia, USA) was used to generate the statistical analysis and the regression models for the physical and oxidative parameters of the emulsions. Firstly, the output variables ( $\mathrm{Y}$ : viscosity at day 1 , droplet size at day 1 , creaming at day 12 , peroxide values at day 12 and volatile compounds at day 12) were related to the input variables (X: fish oil content, total content of CAS plus PC and ratio between CAS and PC) by second degree polynomials as follows, Eq. 3:

$\mathrm{Y}=\mathrm{b}_{0}+\sum_{\mathrm{i}=1}^{3} \mathrm{~b}_{\mathrm{i}} \mathrm{X}_{\mathrm{i}}+\sum_{\mathrm{i}=1}^{3} \mathrm{~b}_{\mathrm{ii}} \mathrm{X}_{\mathrm{i}}^{2}+\sum_{\mathrm{i}<\mathrm{j}}^{3} \mathrm{~b}_{\mathrm{ij}} \mathrm{X}_{\mathrm{i}} \mathrm{X}_{\mathrm{j}}$ (Equation 3)

where the coefficients $b_{i}$ and $b_{i i}$ are related to the linear and quadratic effects, respectively, of each input factor on the output variable and the cross-product coefficients $b_{i j}$ represent the interactions between two input variables. Coefficient $b_{0}$ indicates the mean change in viscosity, droplet size and creaming, primary oxidation product formation, etc., when the fish oil content, total emulsifier content, and ratio between emulsifiers are 0 . Secondly, the analysis of variance (ANOVA) was carried out using Fisher's least significant difference test. The significance of all terms in the models was judged statistically by computing the $p$-value at a confidence level $1-\alpha=95 \%$. The quadratic models were then used to generate contour maps and to find the optimal values of the input variables, which maximize the quality of the emulsions in terms of physical and oxidative stability, by using RSM (Myers, Montgomery \& Anderson-Cook, 2002).

\section{Results and discussion}

\subsection{Characterization of emulsions}

\subsubsection{Droplet size}


Droplet size results were significantly affected by the linear effect of all input variables studied (fish oil content, total emulsifier amount and ratio of CAS to PC) as well as the quadratic effect of fish oil content (Table 2). Droplet size at day 1 , with $D[4,3]$ values ranging from 6.31 to 21.19 $\mu \mathrm{m}$, decreased with increasing fish oil content, total emulsifier content and ratio of CAS to PC (Table 1). García-Moreno et al. (2014) reported that $10 \%$ fish oil-in-water emulsion stabilized with $0.3 \% \mathrm{w} / \mathrm{w}$ CAS and $0.5 \% \mathrm{w} / \mathrm{w}$ PC had a $D[3,2]$ value of $210 \mathrm{~nm}$. Another study on $20 \%$ oil-in-water emulsions stabilized with $0.5 \% \mathrm{w} / \mathrm{w}$ CAS and $0.5 \% \mathrm{w} / \mathrm{w}$ egg-PC emulsifiers showed an average droplet size of $320 \mathrm{~nm}$ (Fang et al., 1996). The larger droplet sizes observed in our study compared to these studies were most likely due to the total emulsifier content and the ratio between total emulsifier and fish oil content, as well as homogenizer type.

Droplet sizes of 50-2.1-0.4, 50-2.1-2, 50-2.8-1.2, 60-1.4-0.4, 70-2.1-0.4, and 70-2.1-2 significantly increased after 12 days of storage. The rest of the emulsions were stable in terms of droplet size during 12 days storage (Table 1). Droplet size decreased 2 to 3 folds for emulsions produced with $70 \%$ fish oil content compared to $50 \%$, when having the same amount of emulsifier content and ratio of CAS to PC (e.g. emulsions 50-1.4-1.2 vs 70-1.4-1.2 or 50-2.1-2 vs 70-2.1-2) (Table 1). In these emulsions, the decrease in the droplet size could be due to the increase in the dispersed phase volume fraction from $50 \%$ to $70 \%$, which increased the viscosity of the whole emulsion. Higher viscosity occurs due to a high volume fraction of dispersed phase, so that droplet packing itself gives rise to higher viscosity. This high volume occupancy of the dispersed phase not only led to a high viscosity, but also allowed the mixer blade to perform better in disruption of the oil droplets during 
homogenization. Moreover, Hadnadev, Dokic, Krstonosic \& Hadnadev (2013) also reported that increased oil concentration resulted in increased specific surface area at $20 \%$ emulsifier concentration. As expected, droplet size decreased when the total amount of emulsifiers were increased while oil content and ratio between CAS to PC were kept constant (see values for emulsions 50-1.4-1.2 and 50-2.8-1.2, 60-1.4-2 and 60-2.8-2, or 70-1.4-1.2 and 70-2.8-1.2 in Table 1). This was due to the higher amount of emulsifier available during the emulsion production, which resulted in smaller droplets. The difference between droplet sizes of 50-1.41.2 and $70-2.8-1.2$ was even larger $(\mathrm{D}[4,3]$ values of 20.68 and $6.31 \mu \mathrm{m}$, respectively), which supports the mutual effect of increasing both fish oil (from 50 to $70 \%$ ) and total emulsifier (from 1.4 to $2.8 \%$ ) contents.

Ratio of CAS to PC also had a significant effect on decreasing droplet size, with a negative correlation (Table 2). This may be attributed to a superior emulsifying ability of CAS. Moreover, the higher amount of CAS led to smaller droplet sizes due to the higher amount of CAS available during the droplet disruption in the mixer. Results indicated that, when the ratio of CAS to PC was increased, the decrease in droplet size was more pronounced when fish oil content was increased (Table 1). For instance, a reduction in $D[4,3]$ from 21.19 to $18.94 \mu \mathrm{m}$ was observed for samples 50-2.1-0.4 and 50-2.1-2, whereas a more pronounced reduction in $\mathrm{D}[4,3]$ (from 11.84 to $6.73 \mu \mathrm{m}$ ) was found for samples 70-2.1-0.4 and 70-2.1-2 (Table 1). As explained above, this added effect was also attributed to higher viscosity of the system when the amount of dispersed phase was increased.

The obtained quadratic model adequately explained the experimental data $\left(R^{2}=0.9896\right.$, Table 2). Thus, optimization was carried out using this model in order to find the optimal values for the input variables that minimized droplet size. A smaller droplet size is more 
favorable in high fat emulsions as it increases the physical stability leading to less creaming compared to larger droplet sizes. The optimal recipe suggested by RSM was $70 \%$ fish oil, $2.8 \%$ total emulsifier and a ratio of CAS to PC of 2 (Table 3, Supplementary Fig. 1a), which correlates well with the significant effect of each input variable and their negative correlation with droplet size.

\subsubsection{Apparent viscosity}

All emulsions were non-Newtonian and showed shear thinning behavior. Emulsions were stable in terms of viscosity, showing similar values of apparent viscosity at $20 \mathrm{~s}^{-1}$ on day 1 and 12 . There was only one emulsion (70-2.1-0.4) that had a significant decrease in viscosity during 12 days of storage (Table 1). At day 1 , apparent viscosity of samples was significantly influenced by the linear and quadratic effects of fish oil content and the interaction between fish oil content and total emulsifier. On the other hand, linear and quadratic effects of total emulsifier content and the ratio between emulsifiers as well as the other interactions between factors did not have a significant effect on viscosity (Table 2). Apparent viscosity of samples increased with increasing fish oil content. Emulsions prepared with 50 and $60 \%$ of fish oil had apparent viscosities from 17.76 to $107.07 \mathrm{mPa} \cdot \mathrm{s}$, while emulsions with $70 \%$ fish oil content gave apparent viscosities between 446.24 and $1132.21 \mathrm{mPa} \cdot \mathrm{s}$ on day 1 (Table 1). This might be due to the lower droplet size of emulsions containing higher amount of oil. Smaller droplets led to more friction between oil droplets, which were caused by expanded surface-to-volume ratio of the dispersed phase. It resulted in less mobility of the droplets in the emulsion and therefore higher viscosity compared to emulsions having larger droplets (Pal, 1996).

Emulsions with high viscosity are preferred in order to reduce creaming, as a consequence of a reduced mobility of oil droplets in the water phase. However, high viscosity might hamper 
applications of delivery emulsions in liquid-based food systems (e.g. milk, soft-drinks). Therefore, optimal level of viscosity needs to be set depending on the food matrix to which the emulsion will be added.

Optimization of viscosity was carried out by means of the quadratic model obtained, which explained the experimental data to a large extent $\left(R^{2}=0.9637\right.$, Table 2$)$. However, lack-of-fit test indicated that the selected model did not adequately describe the observed data ( $p$-value 0.0015). According to RSM results, the optimum recipe to obtain minimum viscosity was $59 \%$ of fish oil content, $1.4 \%$ total emulsifier and 0.4 ratio of CAS to PC (Table 3, Supplementary Fig. 1b). To maximize viscosity, RSM suggested fish oil content, total emulsifier content and ratio of CAS to $\mathrm{PC}$ as $70 \%, 2.8 \%$ and 2 , respectively.

\subsubsection{Creaming}

Increasing fish oil content, total emulsifier content and the ratio of CAS to PC significantly increased creaming stability (Fig. 1, Table 2). Particularly, the effect of fish oil content on creaming was highly significant $(\mathrm{p}<0.000)$. Emulsions produced with $50 \%$ fish oil showed creaming between 25 to $30 \%$ already at the first day of the storage, whereas emulsions with $60 \%$ and $70 \%$ fish oil contents had 5 to $17 \%$ and 0 to $3 \%$ creaming at day 1 , respectively (Fig. 1). Likewise, our previous study of high fat fish oil-in-water emulsions stabilized with combinations of CAS and alginate also showed that emulsions containing $70 \%$ oil resulted in less creaming than emulsions with 50 or $60 \%$ oil (Yesiltas et al., 2017).

It was observed that emulsions produced with 0.4 ratio of CAS to PC had reduced stability to creaming compared to the ratio 2.0 when emulsions had the same fish oil and total emulsifier contents (Fig. 1). This suggested that the higher the CAS amount, the better the creaming stability. This may be due to the ability of CAS to form a thick interfacial layer with a negative 
surface charge (at $\mathrm{pH} 7)$, which decreased droplet coalescence (Elias, Kellerby \& Decker, 2008). Additionally, creaming was more intense for the emulsions with $1.4 \%$ emulsifier content in comparison with $2.8 \%$ when the fish oil content and the ratio of CAS to PC were kept at the same levels (Fig. 1). Among all emulsions produced, only 70-2.1-2 and 70-2.8-1.2 did not show any creaming, which was presumably due to the fact that they were packed with oil droplets and thus the strong steric and electrostatic repulsion dominated the emulsion stability, thereby limiting the creaming (Fig. 1).

Table 2 shows that the proposed quadratic model explained the variability of creaming data to a large extent $\left(R^{2}=0.9992\right)$. Observed vs. predicted values were also plotted and shared in Supplementary Fig.1c. Thus, it was used for obtaining the optimal values of the input variables that minimized creaming. In this regard, the optimal recipe given by RSM was $70 \%$ fish oil content, $2.8 \%$ total emulsifier and a ratio of 2 for CAS to PC (Table 3, Supplementary Fig.1c). This also showed the positive effect of having a high ratio of CAS to PC against creaming.

\subsection{Lipid oxidation measurements of emulsions}

\subsubsection{Primary oxidation products - peroxide value (PV)}

All CAS+PC emulsions were found to be quite oxidatively stable with the highest PV after 12 days of storage of 5.07 meq peroxides/kg oil (Fig. 2). Likewise, Horn et al. (2012) showed that $70 \%$ fish oil-in-water emulsions emulsified with $2.8 \%$ CAS had 0.5 meq peroxides $/ \mathrm{kg}$ oil PV at the end of one week of storage. Compared with PV results obtained after one week of storage in the current study showed that, at this time point PVs were approximately 2-3 meq peroxides $/ \mathrm{kg}$ oil. This finding indicates that partly replacing CAS with PC did not reduce the formation of hydroperoxides compared to emulsions produced with only CAS. The advantage 
of having CAS in terms of increasing oxidative stability in the emulsions could be due to its ability to bind transition metal ions both in water phase and at the interface (Horn et al., 2012; Elias et al., 2008).

It is noteworthy that most of the emulsions had severe creaming instability (Fig. 1), which might have physically limited the oxidation of the emulsions. Therefore, care should be taken when samples are compared. Emulsions with $50 \%$ fish oil content had $25 \%$ creaming at the end of the $1^{\text {st }}$ day of storage meaning that the half of the water phase was already separated. In the upper part of the bottle for the same volume, creamed emulsion had a lower amount of water phase. Thereby, a lower total amount of metal ions/prooxidants was available for interaction in the proximity of oil droplets, compared to a non-creamed emulsion. Due to the close packing, diffusion of metal ions would also be more difficult. Thus, formation of oxidation products presumably was less than expected compared to an emulsion without creaming. However, droplets in the cream layer are located closer to the air; therefore, they are expected to be more exposed to oxygen diffusion, compared to droplets in a non-creamed emulsion. Also, there is a high possibility for the prooxidants/oxidation products to be involved in droplet-droplet exchange in a creamed emulsion compared to non-creamed one. These factors could thus have favored oxidation for creamed emulsions; however, this was not the case. On the other hand, emulsions with $70 \%$ fish oil content had low or no creaming, which might have favored the contact of prooxidants in the water phase with the lipid droplets. Hence, the factors that could reduce lipid oxidation in creamed emulsions seemed more important.

Only emulsions 70-2.8-1.2 and 70-2.1-2 did not have any creaming during storage, with 702.8-1.2 presenting a lower PV compared to 70-2.1-2. The lower PV found in 70-2.8-1.2 could 
be explained by a different content of CAS and PC and the antioxidant properties of these emulsifiers. Emulsion 70-2.8-1.2 had higher CAS and PC content (7.64 g CAS + 6.36 g PC in 500 grams of emulsion) compared to emulsion $70-2.1-2(7.00 \mathrm{~g} \mathrm{CAS}+3.50 \mathrm{~g} \mathrm{PC}$ in 500 grams of emulsion). CAS exhibits metal chelating activity and can trap metal ions present in the aqueous phase. CAS also hinders the access of metals to the water-oil interface by creating a thick interface (Horn et al., 2012; Elias et al., 2008). Moreover, PC might have retarded lipid oxidation by its metal chelating and radical scavenging activities, regenerating tocopherols and converting hydroperoxides into stable compounds (García-Moreno et al., 2014; Pan, Tikekar \& Nitin, 2013).

The experimental data was not explained well with the obtained quadratic model $\left(R^{2}=\right.$ 0.5863 , Table 2). Nevertheless, according to RSM results, $70 \%$ fish oil content, $2.8 \%$ total emulsifier and 2 as the ratio of CAS to PC led to a minimum formation of primary oxidation products (Table 3, Supplementary Fig. 1d).

\subsubsection{Tocopherol content}

The initial alpha-, beta-, gamma- and delta-tocopherol contents of the cod liver oil were $250 \pm$ $1.9,0 \pm 0,118 \pm 1.2$ and $48 \pm 0.9 \mathrm{mg} / \mathrm{kg}$, respectively. For the emulsions, alpha-, gammaand delta-tocopherols were quantified and were in the range of $103.2 \pm 9.0-152.3 \pm 3.1,17.9$ $\pm 1.6-24.9 \pm 0.5,44.7 \pm 3.6-61.7 \pm 0.9 \mathrm{mg} / \mathrm{kg}$ emulsion, respectively on day 0 (see Supplementary Fig. 2). There was a significant decrease in delta-tocopherol for all the emulsion samples, when day 0 and day 12 results were compared, except for emulsions 50 1.4-1.2, 50-2.1-2, 60-1.4-0.4 and 60-1.4-2 ( $\mathrm{p}<0.05)$. Alpha- and gamma-tocopherol contents of emulsions did not decrease significantly from day 0 to 12 , apart from emulsions 70-2.8-1.2, 60-2.1-1.2 and 50-2.1-0.4. Emulsions 70-2.8-1.2 had a significant decrease in alpha- 
tocopherol, whereas 60-2.1-1.2 had a significant decrease in both alpha- and gammatocopherols, and 50-2.1-0.4 had a significant decrease in gamma-tocopherol. Emulsion 702.8-1.2 had the highest $P V$ at day 5 and emulsion $60-2.1-1.2$ had one of the highest $P V$ at day 12. Therefore, the formation of primary oxidation products during storage for these two emulsions may have been higher if tocopherols had not been consumed during storage as a consequence of their antioxidant activity.

RSM results suggested similar optimal values for different types of tocopherols in order to obtain higher levels of tocopherols on day 12 data (Supplementary Fig. 1e-g). As shown in Table 3, optimal recipes for higher tocopherol levels were obtained for $70 \%$ fish oil content, $2.8 \%$ total emulsifier content and $0.40-0.42$ as the ratio of CAS to PC. Higher levels of alpha-tocopherol was significantly affected by the fish oil content and the ratio of CAS to PC; increasing fish oil content and PC increased the amount of alpha-tocopherol (Table 2). On the other hand, delta- and gamma-tocopherols were only increased significantly by the increasing amount of fish oil content (Table 2). As tocopherols are antioxidants and were consumed during the storage of the emulsions, it is preferable to track the changes as an indicator of oxidation and antioxidation.

\subsubsection{Secondary oxidation products - dynamic head space (DHS) GC-MS}

Formation of volatile compounds was quantified on days 0 and 12 . Fig. 3 shows the concentration of 1-penten-3-ol, (E)-2-pentenal, $(E)$-2-hexenal and $(E, E)$-2,4-heptadienal in emulsions. These volatiles were selected due to their higher concentration in the emulsions compared to other volatile compounds and also because they originate from oxidation of omega-3 PUFAs such as eicosapentaenoic acid (EPA) and docosohexaenoic acid (DHA) (Genot, Meynier \& Riaublanc, 2003). Similarly to the findings for PV, emulsions with $50 \%$ fish 
oil content had lower contents of volatile compounds compared to emulsions produced with $70 \%$ fish oil content (Fig. 3), which presumably was also affected by their creaming index as discussed under section 3.2.1.

For emulsions without creaming, emulsion 70-2.8-1.2 had significantly lower content of secondary volatile oxidation products compared to emulsion 70-2.1-2, except for (E)-2pentenal (Fig.3). This could be due to the higher content of emulsifiers in emulsion 70-2.8-1.2 (7.64 g CAS + $6.36 \mathrm{~g} \mathrm{PC})$ compared to $70-2.1-2$ (7.00 g CAS + $3.50 \mathrm{~g}$ PC) which was basically related to CAS and PC's antioxidant activities (similar reasons as explained in detail in section 3.2.1 for PV). When 70-2.1-0.4 and 70-2.1-2 were compared, 70-2.1-0.4 having higher amount of PC showed better oxidative stability in terms of formation of $(E, E)-2,4-$ heptadienal and 1-penten-3-ol (Fig. 3). A previous study showed that $70 \%$ fish oil-in-water emulsion stabilized with $2.8 \%$ CAS had $92 \mathrm{ng} / \mathrm{g}(E, E)-2,4$-heptadienal formed after 7 days of storage (Horn et al., 2012), whereas a lower formation of $(E, E)-2,4$-heptadienal $(33.2 \mathrm{ng} / \mathrm{g})$ after 12 days of storage was found in this study when replacing $45 \%$ of CAS with PC in $70 \%$ fish oil-in-water emulsions. This could be due to the improved interfacial properties provided by PC because of its interaction with CAS at the interface and also to the radical scavenging and metal chelating activity of PC (García-Moreno et al., 2014; Berton-Carabin et al., 2014; Bandarra et al., 1999).

When emulsions 70-1.4-1.2 (5\% creaming) and 70-2.8-1.2 (no creaming) were compared, oxidative stability was found to be higher for the one with higher total emulsifier content (Fig. 3). This might be due to a better coverage of the oil-water interface with higher amount of CAS and PC by forming a thicker interface, which is expected to limit the diffusion of prooxidants (e.g. metal ions) from the water phase to the oil phase. Moreover, antioxidant 
properties of adsorbed CAS and PC at the interface and presence of un-adsorbed CAS and PC in the water phase might have increased the oxidative stability of emulsion with higher total emulsifier content.

RSM results provided different optimal values for different types of volatile compounds (Table 3, Supplementary Fig. 1h-s). Therefore, it is not possible to select one optimal recipe for decreasing the formation of volatile compounds. However, optimal recipes to minimize the content of 1-penten-3-ol, $(E)$-2-pentenal, $(E)$-2-hexenal and $(E, E)$-2,4-heptadienal, which were formed in higher concentrations compared to other volatile compounds, were suggested to have low fish oil content $(50-53 \%)$ and low ratio of CAS to PC $(0.40-0.42)$. Therefore, these suggested optimal recipes may have led to the conclusion that low fish oil and high PC content prevent the formation of the most abundant volatile compounds in the emulsions, providing a higher oxidative stability for emulsions stabilized with combinations of CAS and PC. However, this cannot be the case since the emulsions prepared by low fish oil and high PC content were not physically stable and severe creaming was observed during storage limiting oxidation as previously explained. Hence, only emulsions without creaming can be considered for selection of the optimal recipe due to higher physical stability.

\section{Conclusion}

In conclusion, results confirmed the hypothesis that it was possible to produce physically and oxidatively stable high fat fish oil-in-water emulsion stabilized with combinations of CAS and PC. Creaming was dramatically affected by fish oil content. Emulsions showed significantly less creaming, smaller droplet size with increasing fish oil content, total emulsifier content and ratio of CAS to PC. Viscosity increased significantly with increased fish oil content. RSM results showed that viscosity could be decreased/ increased by decreasing/ increasing the 
ratio of CAS to PC, respectively. Among the physically stable emulsions, 70-2.8-1.2 showed the lowest peroxide value and formation of volatile compounds. Therefore, it was considered as the optimal formula as it had the smallest droplet size, did not cream and oxidative stability was acceptable. This study also showed that the substitution of some of the CAS with PC increased oxidative stability of the emulsions while maintaining the physical stability again confirming the original hypothesis.

\section{Abbreviations used}

CAS - sodium caseinate

DHA - docosohexaenoic acid

DHS - dynamic head space

EPA - eicosapentaenoic acid

PC - phosphatidylcholine

PV - peroxide value

RSM - Response Surface Methodology

\section{Acknowledgments}

We would like to thank Lipoid $\mathrm{GmbH}$, Arla Foods Ingredients amba and Maritex AS Norway for donating phosphatidylcholine, sodium caseinate and cod liver fish oil, respectively. Furthermore, we are grateful to Inge Holmberg and Thi Thu Trang Vu for their skillful work in the laboratory. Finally, we would like to thank the Danish Council for Independent Research Technology and Production Sciences for financing the project Mapping and Characterizing of Lipid Oxidation in Emulsified Systems (MAPOX).

The authors have declared no conflict of interest.

\section{References}


AOCS Official Method Ce 8-89. (1998). Determination of tocopherols and tocotrienols in vegetable oils and fats by HPLC. AOCS: Champaign, IL, USA.

Bandarra, N. M., Campos, R. M., Batista, I., Nunes, M. L. \& Empis, J. M. (1999). Antioxidant synergy of $\alpha$-tocopherol and phospholipids. Journal of the American Oil Chemists Society, 76, 905-913.

Bermudez-Aguirre, D. \& Barbosa-Canovas, G. (2011). Quality of selected cheeses fortified with vegetable and animal sources of omega-3. LWT - Food Science and Technology, 7, 1577-84.

Berton-Carabin, C. C., Ropers, M. H. \& Genot, C. (2014). Lipid Oxidation in Oil-in-Water Emulsions: Involvement of the Interfacial Layer. Comprehensive Reviews in Food Science and Food Safety, 13 (5), 945-977.

Bligh, E. G. \& Dyer, W. J. (1959). A rapid method of total lipid extraction and purification. Canadian Journal of Biochemistry and Physiology, 37, 911-917.

Diaz, M., Dunn, C. M., McClements, D. J. \& Decker, E. A. (2003). Use of caseinophosphopeptides as natural antioxidants in oil-in-water emulsions. Journal of Agricultural and Food Chemistry, 51, 2365-2370.

Elias, R. J., Kellerby, S. S. \& Decker, E. A. (2008). Antioxidant Activity of Proteins and Peptides. Critical Reviews in Food Science and Nutrition, 48, 430-441.

Fang, Y. \& Dalgleish, D. G. (1996). Comparison of the effects of three different phosphatidylcholines on casein-stabilized oil-in-water emulsions. Journal of the American Oil Chemists`Society, 73(4), 437-442. 
Gao, Z., Huang, Y., Zhao, J., Yao, X., Zhang, K., Fang, Y., Nishinari, K., Philips, G. O. \& Yang, H. (2017). Edible Pickering emulsion stabilized by protein fibrils: Part 2. Effect of dipalmitoyl phosphatidylcholine (DPPC). Food Hydrocolloids, 71, 245-251.

García-Moreno, P. J., Horn, A. F. \& Jacobsen, C. (2014). Influence of casein-phospholipid combinations as emulsifier on the physical and oxidative stability of fish oil-in-water emulsions. Journal of Agricultural and Food Chemistry, 62(5), 1142-1152.

Genot, C., Meynier, A. \& Riaublanc, A. (2003). Chapter 7: Lipid Oxidation in Emulsions. In Lipid Oxidation Pathways, edition no. 1; Kamal-Eldin, A; AOCS Publishing: New York. Hadnadev, T. D., Dokic, P., Krstonosic, V. \& Hadnadev, M. (2013). Influence of oil phase concentration on droplet size distribution and stability of oil-in-water emulsions. European Journal of Lipid Science and Technology, 115, 313-321.

Horn, A. F., Nielsen, N. S., Andersen, U., Søgaard, L. H., Horsewell, A. \& Jacobsen, C. (2011). Oxidative stability of $70 \%$ fish oil-in-water emulsions: Impact of emulsifiers and $\mathrm{pH}$. European Journal of Lipid Science and Technology, 113, 1243-1257. Horn, A. F., Nielsen, N. S. \& Jacobsen, C. (2012). Iron-mediated lipid oxidation in $70 \%$ fish oil-in-water emulsions: effect of emulsifier type and pH. International Journal of Food Science and Technology, 47, 1097-1108.

Horn, A. F., Barouh, N., Nielsen, N. S., Baron, C. P. \& Jacobsen, C. (2013). Homogenization pressure and temperature affect protein partitioning and oxidative stability of emulsions. Journal of the American Oil Chemists`Society, 90, 1541-1550. 
Jacobsen, C., Meyer, S. A., Adler-Nissen, J. (1999). Oxidation mechanisms in real food emulsions: Oil-water partition coefficients of selected volatile off-flavor compounds in mayonnaise. Zeitschrift Fur Lebensmittel-Untersuchung Und -Forschung, 208, 317-327. Kolanowski, W., Jaworska, D. \& Weißbrodt, J. (2007). Importance of instrumental and sensory analysis in the assessment of oxidative deterioration of omega-3 long-chain polyunsaturated fatty acid-rich foods. Journal of the Science of Food and Agriculture, 87, 181-191.

Let, M. B., Jacobsen, C. \& Meyer, A. S. (2007). Lipid oxidation in milk, yoghurt, and salad dressing enriched with neat fish oil or pre emulsified fish oil. Journal of Agricultural and Food Chemistry, 55, 7802-7809.

Magnusson, E., Nilsson, L. \& Bergenståhl, B. (2016). Effect of the dispersed state of phospholipids on emulsification—Part1. Phosphatidylcholine. Colloids and Surfaces A: Physicochemical and Engineering Aspects, 506, 794-803.

McClements, J. D. (1999). Chapter 5: Interfacial properties and their characterization. In Food Emulsions: Principles, Practice and Techniques (pp.136), Edition no. 1; CRC Press LCC: Boca Raton, Florida.

McClements, D., Decker, E. \& Weiss, J. (2007). Emulsion-based delivery systems for lipophilic bioactive components. Journal of Food Science, 72(8), R109-R124.

Myers, R. H., Montgomery, D. C. \& Anderson-Cook, C. M. (2002). Process and Product Optimization Using Designed Experiments. In Response Surface Methodology, edition no. 3; Wiley: Hoboken, New Jersey. 
Nichols, P. D., McManus, A., Krail, K., Sinclair, A. J. \& Miller, M. (2014). Recent advances in omega-3: Health benefits, sources, products and bioavailability. Nutrients, 6, 3727-3733. Pal, R. (1996). Effect of Droplet Size on the Rheology of Emulsions. American Institute of Chemical Engineers Journal, 42(11), 3181-3190.

Pan, Y., Tikekar, R. V. \& Nitin, N. (2013). Effect of antioxidant properties of lecithin emulsifier on oxidative stability of encapsulated bioactive compounds. International Journal of Pharmaceutics, 450, 129-137.

Papanikolaou, Y., Brooks, J., Reider, C. \& Fulgoni III, V.L. (2014). U.S. adults are not meeting recommended levels for fish and omega-3 fatty acid intake: results of an analysis using observational data from NHANES 2003-2008. Nutrition Journal, 13, 31.

Scuriatti, M. P., Tomás, M. C. \& Wagner, J. R. (2003). Influence of soybean protein isolatesphosphatidylcholine interaction on the stability of oil-in-water emulsions. Journal of the American Oil Chemists`Society, 80(11), 1093-1100.

Shantha, N. C. \& Decker, E. A. (1994). Rapid, sensitive, ironbased spectrophotometric methods for determination of peroxide values of food lipids. Journal of AOAC International, $77,421-424$.

Song, C., Shieh, C., Wu, Y., Kalueff, A., Gaikwad, S. \& Su, K.-P. (2016). The role of omega-3 polyunsaturated fatty acids eicosapentaenoic and docosahexaenoic acids in the treatment of major depression and Alzheimer's disease: Acting separately or synergistically? Progress in Lipid Research, 62, 41-54. 
Sui, X., Li, Q., Wang, Z., Qi, B., Zou, X., Li, Y. \& Jiang, L. (2016). Does the hydrophobic group on sn-2 position of phosphatidylcholine decide its emulsifying ability? LWT Food Science and Technology, 74, 255-262.

Sünder, A., Scherze, I. \& Muschiolik, G. (2001). Physico-chemical characteristics of oil-inwater emulsions based on whey protein-phospholipid mixtures. Colloids and Surfaces B: Biointerfaces, 21, 75-85.

Sznitowka, M., Janicki, S., Dabrowska, E. \& Zurowska-Pryczkowska, K. (2001). Submicron emulsions as drug carriers. Studies on destabilization potential of various drugs. European Journal of Pharmaceutical Sciences, 12, 175-179.

Waraho, T., McClements, D. J. \& Decker, E. A. (2011). Mechanisms of lipid oxidation in food dispersions. Trends Food Science and Technology, 22, 3-13.

Wysoczanski, T., Sokoła-Wysoczanska, E., Pekala, J., Lochynski, S., Czyz, K., Bodkowski, R., Herbinger, G., Patkowska-Sokola, B. \& Librowski, T. (2016) Omega-3 fatty acids and their role in central nervous system: A review. Current Medicinal Chemistry, 23-28, 816-831.

Xue, J. \& Zhong, Q. (2014). Thyme oil nanoemulsions coemulsified by sodium caseinate and lecithin. Journal of Agricultural and Food Chemistry, 62, 9900-9907.

Yesiltas, B., García-Moreno, P. J., Sørensen, A.-D., M. \& Jacobsen, C. (2017). Physical and oxidative stability of high fat fish oil-in-water emulsions stabilized with combinations of sodium caseinate and sodium alginate. European Journal of Lipid Science and Technology, 119, 1600484.

\section{Figure captions}

Table 1. Experimental design, droplet size and viscosity of emulsions 
Table 2. Polynomial coefficients and $p$-values for the response variables (creaming, droplet size, viscosity, peroxide value, volatile compounds and tocopherols)

Table 3. Optimum recipes for each output variable given by RSM analysis (Optimal recipes were obtained in order to minimize each output variable, only tocopherols were maximized) Figure 1. Creaming index of emulsions during 12 days of storage (Emulsion codes represent amount of fish oil - CAS+PC - CAS:PC, respectively. CAS: sodium caseinate, PC: phosphatidylcholine. $n=1$.)

Figure 2. Formation of primary oxidation products in the emulsions during 12 days of storage (Emulsion codes represent amount of fish oil - CAS+PC - CAS:PC, respectively. CAS: sodium caseinate, PC: phosphatidylcholine. $n=2$.)

Figure 3. Content of secondary volatile oxidation products during 12 days of storage (Emulsion codes represent amount of fish oil - CAS+PC - CAS:PC, respectively. CAS: sodium caseinate, PC: phosphatidylcholine. $n=3$.)

Figure 1. Creaming index of emulsions during 12 days of storage

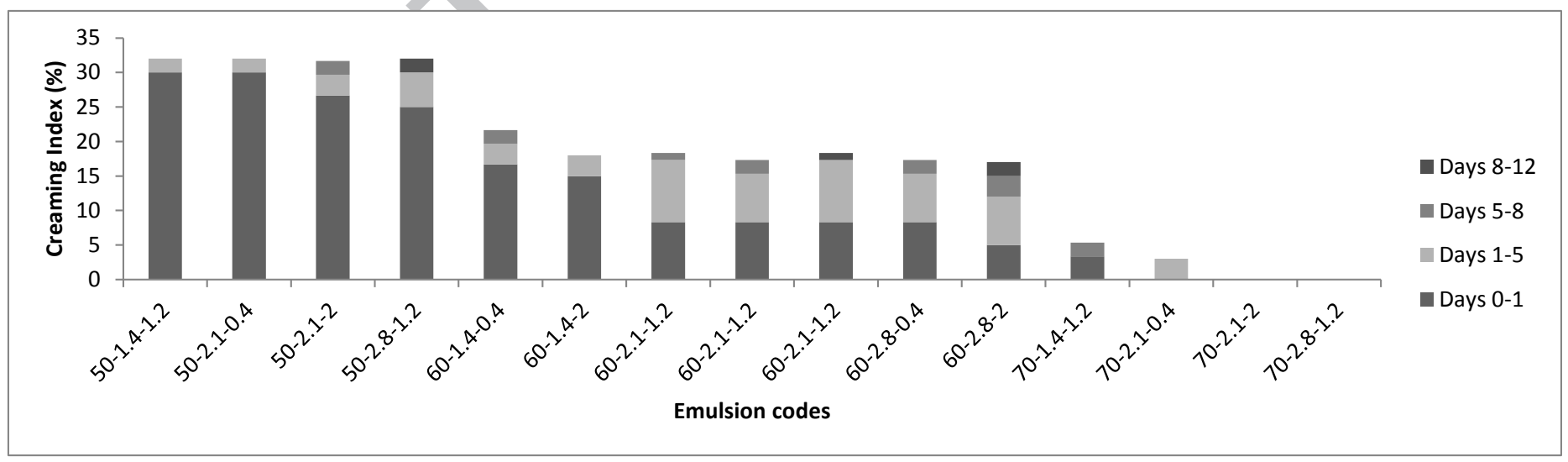

Emulsion codes represent: amount of fish oil, $C A S+P C$ and CAS:PC, respectively. $C A S=$ sodium caseinate, $\mathrm{PC}=$ phosphatidylcholine. $\mathrm{n}=1$. 
Figure 2. Formation of primary oxidation products in the emulsions during 12 days of storage

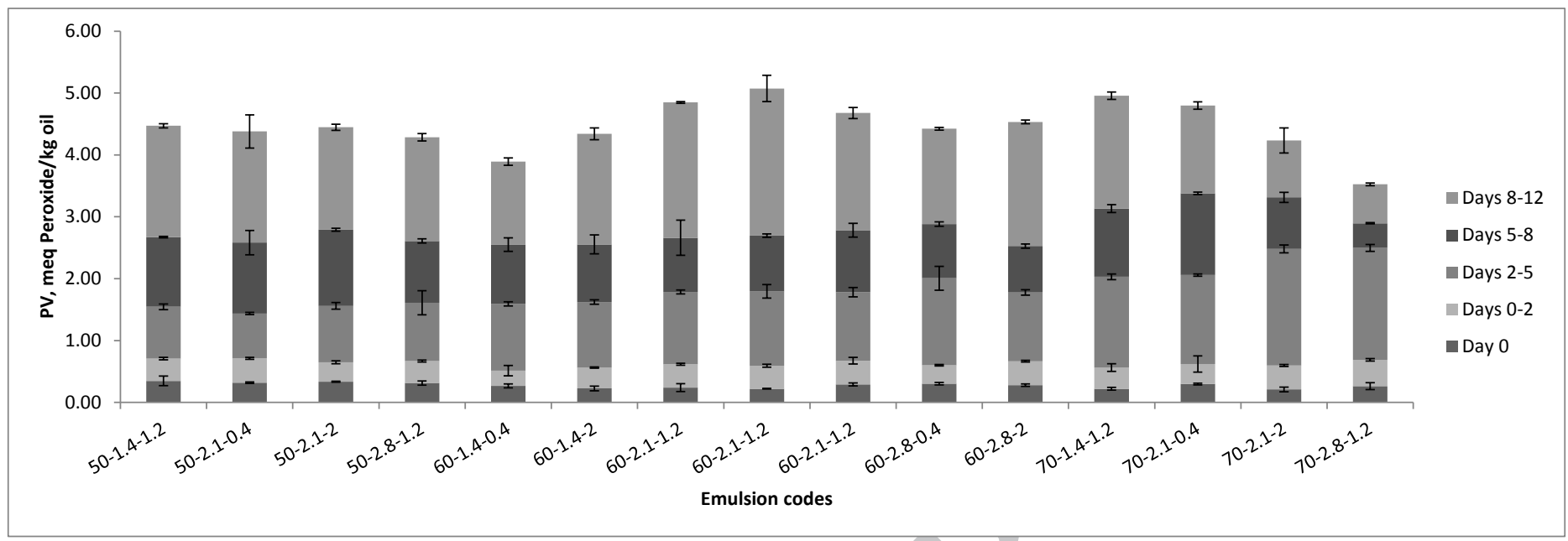

Emulsion codes represent: amount of fish oil, $C A S+P C$ and $C A S: P C$, respectively. $C A S=$ sodium caseinate, $\mathrm{PC}=$ phosphatidylcholine. $\mathrm{n}=2$.

Figure 3. Content of secondary volatile oxidation products during 12 days of storage

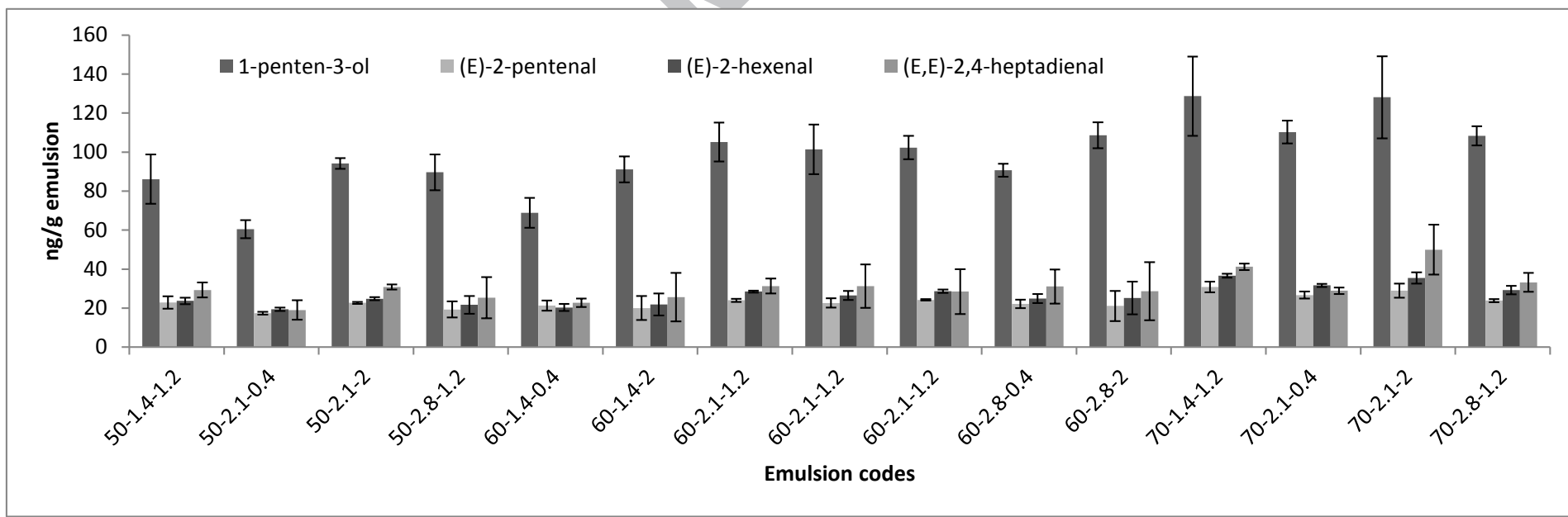

Emulsion codes represent: amount of fish oil, $\mathrm{CAS}+\mathrm{PC}$ and $\mathrm{CAS}: \mathrm{PC}$, respectively. $\mathrm{CAS}=$ sodium caseinate, $\mathrm{PC}=$ phosphatidylcholine. $\mathrm{n}=3$.

Table 1. Experimental design, droplet size and viscosity of emulsions

\begin{tabular}{llllllll} 
Emulsion & Fish oil, & CAS+PC, & CAS:PC, & \multicolumn{2}{l}{ Droplet Size D[4,3] $(\boldsymbol{\mu m})$} & \multicolumn{2}{c}{ Viscosity $\left(\mathrm{mPa} \cdot \mathbf{s} @ 20 \mathbf{s}^{-1}\right)$} \\
Code $^{\mathrm{a}}$ & $\%$, w/w & $\%$, w/w & Ratio & Day 1 & Day 12 & Day 1 & Day 12 \\
\hline $\mathbf{5 0 - 1 . 4 - 1 . 2}$ & 50 & 1.4 & 1.2 & 20.68 & 24.02 & 17.76 & 17.63
\end{tabular}




\begin{tabular}{|c|c|c|c|c|c|c|c|c|}
\hline $50-2.1-0.4$ & 50 & 2.1 & 0.4 & 21.19 & $24.63^{*}$ & 18.31 & 16.19 & \multirow[t]{2}{*}{$n=2$ for } \\
\hline $50-2.1-2$ & 50 & 2.1 & 2.0 & 18.94 & $20.12^{*}$ & 26.42 & 24.27 & \\
\hline $50-2.8-1.2$ & 50 & 2.8 & 1.2 & 15.95 & $17.66^{*}$ & 30.86 & 29.28 & \multirow[t]{2}{*}{ the } \\
\hline $60-1.4-0.4$ & 60 & 1.4 & 0.4 & 20.80 & $24.44^{*}$ & 35.74 & 33.06 & \\
\hline $60-1.4-2$ & 60 & 1.4 & 2.0 & 18.72 & 20.05 & 52.14 & 47.83 & \multirow[t]{2}{*}{ droplet } \\
\hline $60-2.1-1.2$ & 60 & 2.1 & 1.2 & 16.04 & 16.07 & 75.14 & 69.07 & \\
\hline $60-2.1-1.2$ & 60 & 2.1 & 1.2 & 15.42 & 15.74 & 72.97 & 68.85 & \multirow[t]{2}{*}{ size and } \\
\hline $60-2.1-1.2$ & 60 & 2.1 & 1.2 & 16.40 & $14.90^{*}$ & 71.08 & 67.30 & \\
\hline $60-2.8-0.4$ & 60 & 2.8 & 0.4 & 15.47 & 16.44 & 78.23 & 66.32 & \multirow[t]{2}{*}{ viscosit } \\
\hline $60-2.8-2$ & 60 & 2.8 & 2.0 & 10.61 & 10.80 & 107.07 & 97.59 & \\
\hline $70-1.4-1.2$ & 70 & 1.4 & 1.2 & 13.02 & 13.96 & 446.24 & 436.10 & \multirow{2}{*}{$y$} \\
\hline $70-2.1-0.4$ & 70 & 2.1 & 0.4 & 11.84 & $12.56^{*}$ & 522.70 & $418.16^{*}$ & \\
\hline $70-2.1-2$ & 70 & 2.1 & 2.0 & 6.73 & $8.17^{\star}$ & 968.75 & 903.25 & \multirow{2}{*}{ measur } \\
\hline $70-2.8-1.2$ & 70 & 2.8 & 1.2 & 6.31 & 6.62 & 1132.21 & 1107.18 & \\
\hline
\end{tabular}

ements.

Relative standard deviations (RSDs, \%) for droplet size were lower than 10\% except for the value 24.02 which had RSD as $21 \%$. RSDs for viscosity results were lower than $8.5 \%$ except for the values 78.23 and 17.63 which had RSDs as 10.75 and $14.12 \%$, respectively.

*Significant changes in samples between days 1 and $12(p<0.05)$.

aCode represents amount of fish oil, CAS+PC and CAS:PC, respectively. $C A S=$ sodium caseinate, $\mathrm{PC}=$ phosphatidylcholine

Table 2. Polynomial coefficients and p-values for the response variables (creaming, droplet size, viscosity, peroxide value and volatile compounds)

\begin{tabular}{|c|c|c|c|c|c|c|c|c|c|c|}
\hline & \multicolumn{3}{|l|}{ Creaming } & \multicolumn{3}{|c|}{ Droplet size } & \multicolumn{3}{|l|}{ Viscosity } & \multirow{2}{*}{$\begin{array}{l}\text { Peroxide va } \\
\text { Coefficient }\end{array}$} \\
\hline & Coefficient & Correlation & $p$-value & Coefficient & Correlation & $p$-value & Coefficient & Correlation & $p$-value & \\
\hline Constant & 55.7292 & & & -27.5523 & & & 13.2255 & & & -12.9505 \\
\hline A: fish oil content, $\%$ & 0.2875 & - & 0.0000 & 1.9830 & - & 0.0000 & -0.4191 & + & 0.0003 & 0.3504 \\
\hline B: CAS+PC, \% & 0.8929 & - & 0.0008 & 2.3107 & - & 0.0001 & -1.3875 & + & 0.0602 & 5.8232 \\
\hline C: ratio CAS to PC & 0.1562 & - & 0.0056 & 3.6125 & - & 0.0015 & -0.7172 & + & 0.1863 & 2.3047 \\
\hline AA & -0.0108 & - & 0.0113 & -0.0184 & - & 0.0072 & 0.0032 & + & 0.0029 & -0.0019 \\
\hline$A B$ & -0.1786 & - & 0.0054 & -0.0707 & - & 0.2762 & 0.0239 & + & 0.0337 & -0.0446 \\
\hline AC & -0.0937 & - & 0.0372 & -0.0894 & - & 0.1378 & 0.0137 & + & 0.1150 & -0.0200 \\
\hline BB & 1.3605 & + & 0.0611 & -0.2432 & - & 0.7888 & 0.0196 & + & 0.8795 & -0.7440 \\
\hline BC & 1.7857 & + & 0.0132 & -1.2411 & - & 0.1469 & 0.0089 & + & 0.9343 & -0.1518 \\
\hline CC & 0.2604 & + & 0.5736 & 0.8841 & + & 0.2373 & -0.0202 & - & 0.8383 & -0.3236 \\
\hline $\mathbf{R}^{2}$ & 0.9992 & & & 0.9896 & & & 0.9637 & & & 0.5863 \\
\hline
\end{tabular}




$\begin{array}{lllll}\text { Lack-of-fit } & 0.6148 & 0.2160 & 0.0015 & 0.1201 \\ \text { Standard Error of } & 0.5774 & 0.4957 & 0.0058 & 0.1955 \\ \text { Estimation } & 0.2556 & 0.4218 & 0.0542\end{array}$

Table 2. Continues.

\begin{tabular}{|c|c|c|c|c|c|c|c|c|c|c|c|}
\hline & \multicolumn{3}{|c|}{ 1-penten-3-ol } & \multicolumn{3}{|c|}{ (E)-2-pentenal } & \multicolumn{3}{|c|}{ (E)-2-hexenal } & \multicolumn{2}{|c|}{ (E,E)-2,4-heptac } \\
\hline & Coefficient & Correlation & $p$-value & Coefficient & Correlation & $p$-value & Coefficient & Correlation & $p$-value & Coefficient & Co \\
\hline Constant & -80.0401 & & & 30.8216 & & & 21.8762 & & & 92.2761 & \\
\hline A: fish oil content, $\%$ & -1.0169 & + & 0.0033 & -1.3090 & + & 0.013 & -1.8046 & + & 0.0042 & -3.6504 & + \\
\hline B: CAS+PC, \% & 92.4518 & + & 0.4557 & 15.0393 & - & 0.3016 & 32.6768 & - & 0.854 & 25.4196 & - \\
\hline C: ratio CAS to $\mathrm{PC}$ & 82.0484 & + & 0.0210 & 11.3938 & + & 0.5014 & 14.7484 & + & 0.2565 & -0.7484 & + \\
\hline AA & 0.0434 & + & 0.4324 & 0.0169 & + & 0.2717 & 0.0234 & + & 0.2046 & 0.0351 & + \\
\hline AB & -0.8511 & - & 0.2773 & -0.1221 & - & 0.5445 & -0.1918 & - & 0.4238 & -0.1446 & - \\
\hline AC & -0.4950 & - & 0.4547 & -0.0944 & - & 0.5909 & -0.0491 & - & 0.8092 & 0.2897 & + \\
\hline BB & -8.3427 & - & 0.4582 & -2.2270 & - & 0.4617 & -4.9541 & - & 0.1908 & -3.3274 & - \\
\hline BC & -1.9643 & - & 0.8309 & 0.0937 & + & 0.9697 & -0.5536 & - & 0.8486 & -2.3973 & - \\
\hline CC & -14.1178 & - & 0.1359 & -2.1191 & - & 0.3675 & -3.7070 & - & 0.1994 & -2.6569 & - \\
\hline $\mathbf{R}^{2}$ & 0.9020 & & & 0.8016 & & & 0.8725 & & & 0.7176 & \\
\hline Lack-of-fit & 0.0240 & & & 0.0657 & & & 0.0892 & & & 0.0364 & \\
\hline $\begin{array}{l}\text { Standard Error of } \\
\text { Estimation }\end{array}$ & 1.9583 & & & 0.8757 & & & 1.1985 & & & 1.6139 & \\
\hline Mean absolute error & 4.7712 & & & 1.2983 & & & 1.5783 & & & 3.1751 & \\
\hline
\end{tabular}

Table 2. Continues.

\begin{tabular}{|c|c|c|c|c|c|c|c|c|}
\hline & \multicolumn{3}{|c|}{ Alpha-tocopherol } & \multicolumn{3}{|c|}{ Delta-tocopherol } & \multicolumn{2}{|c|}{ Gamma-tocopherol } \\
\hline & Coefficient & Correlation & $p$-value & Coefficient & Correlation & $p$-value & Coefficient & Correlatio \\
\hline Constant & 135.0240 & & & 15.3823 & & & 5.8010 & \\
\hline A: fish oil content, $\%$ & -1.5838 & + & 0.0022 & 0.7300 & + & 0.0048 & 0.2925 & + \\
\hline B: CAS+PC, \% & -3.8750 & + & 0.1741 & -8.0357 & - & 0.1472 & -2.9286 & - \\
\hline C: ratio CAS to PC & -9.9531 & - & 0.0091 & 2.0625 & - & 0.5037 & 1.5625 & - \\
\hline AA & 0.0190 & + & 0.2323 & -0.0030 & - & 0.7460 & -0.0009 & - \\
\hline AB & 0.4321 & + & 0.1065 & 0.2000 & + & 0.2089 & 0.0786 & + \\
\hline AC & 0.0156 & + & 0.9181 & -0.0156 & - & 0.8853 & -0.0062 & - \\
\hline BB & -3.1718 & - & 0.2993 & -0.9609 & - & 0.6144 & -0.3486 & - \\
\hline BC & -5.4018 & - & 0.1065 & -1.4286 & - & 0.4056 & -0.9375 & - \\
\hline CC & 4.3685 & + & 0.1297 & 0.5534 & + & 0.7001 & 0.2018 & + \\
\hline $\mathbf{R}^{2}$ & 0.9764 & & & 0.9757 & & & 0.9735 & \\
\hline Lack-of-fit & 0.2019 & & & 0.4995 & & & 0.3602 & \\
\hline $\begin{array}{l}\text { Standard Error of } \\
\text { Estimation }\end{array}$ & 2.1502 & & & 1.5308 & & & 0.5774 & \\
\hline Mean absolute error & 1.6489 & & & 0.7756 & & & 0.3522 & \\
\hline
\end{tabular}

Coefficients were regression coefficients obtained from regression models. The regression equation of the fitted model can be formed using Equation 3. 
Correlation ('-' or '+' ) were given based on the estimated effects and interactions, which involves estimating the average or main effect of each experimental factor and interactions between the factors.

The lack-of-fit test is designed to determine whether the selected model is adequate to describe the observed data. The test is performed by comparing the variability of the current model residuals to the variability between observations at replicate settings of the factors. If the $p$-value for lack-of-fit in the ANOVA table is greater or equal to 0.05 , the model appears to be adequate for the observed data at the $95.0 \%$ confidence level. Otherwise, model does not describe the observed data.

Table 3. Optimum recipes for each output variable given by RSM analysis (Optimal recipes were obtained in order to minimize each output variable, only tocopherols were maximized)

\begin{tabular}{|c|c|c|c|c|}
\hline & $\begin{array}{l}\text { Fish oil }(\%, \\
\text { w/w) }\end{array}$ & $\begin{array}{l}\text { Total emulsifier, (CAS+PC) } \\
(\%, w / w)\end{array}$ & Ratio of CAS to PC & Highlights \\
\hline Droplet size & 70 & 2.8 & 2.00 & \\
\hline Viscosity & 59 & 1.4 & 0.40 & Fish oil \\
\hline Creaming Index & 70 & 2.8 & 2.00 & \\
\hline Peroxide value & 70 & 2.8 & 2.00 & content and \\
\hline Alpha-tocopherol & 70 & 2.8 & 0.40 & \\
\hline Delta-tocopherol & 70 & 2.8 & 0.40 & type of \\
\hline Gamma-tocopherol & 70 & 2.8 & 0.42 & \\
\hline 2-Ethyl-furan & 70 & 2.8 & 2.00 & emulsifier \\
\hline 1-Penten-3-one & 70 & 2.8 & 2.00 & \\
\hline 1-Penten-3-ol & 50 & 1.4 & 0.42 & \\
\hline (E)-2-Pentenal & 50 & 2.8 & 0.40 & aттестеd \\
\hline Hexanal & 70 & 1.9 & 2.00 & \\
\hline (E)-2-Hexenal & 50 & 1.4 & 0.41 & stability of fish \\
\hline (Z)-4-Heptenal & 56 & 1.4 & 0.40 & \\
\hline 2-Pentyl-furan & 70 & 2.8 & 2.00 & o/w emulsions \\
\hline (E)-2-Heptenal & 70 & 2.8 & 2.00 & \\
\hline Benzalehyde & 50 & 1.4 & 0.41 & Combini \\
\hline (E,E)-2,4-Heptadienal & 53 & 1.4 & 0.40 & \\
\hline Nonanal & 58 & 2.0 & 2.00 & ng CAS and \\
\hline$(E, Z)-2,6$-Nonadienal & 50 & 1.4 & 0.92 & \\
\hline
\end{tabular}

PC as emulsifiers improved stability of fish o/w emulsions

- Higher CAS+PC content (2.8\%) provided a better oxidative stability compared to $1.4 \%$

- CAS+PC emulsions with $70 \%$ fish oil showed better physical stability compared to $50 \%$ 